\title{
Astroglial Induction of in vivo Angiogenesis
}

\author{
I. Suárez ${ }^{1}$, G. Bodega ${ }^{1}$, M. Rubio' 1 , L.M. García-Segura ${ }^{2}$ and B. Fernández ${ }^{3}$ \\ ${ }^{1}$ Departamento de Biología Celular y Genética, Universidad de Alcalá \\ Instituto Cajal, CSIC \\ ${ }^{3}$ Departamento de Biología Celular, Universidad Complutense, Madrid, Spain
}

\section{SUMMARY}

A purified population of astrocytes was prepared from embryonic rat hypothalamus. These cells were transplanted into the cerebral cortex of adult rats with survival time of 5 days and studied by glial fibrillary acidic protein (GFAP) immunohistochemistry and electron microscopy. A progressive gradation from the edges of the implant to the intact host tissue was observed in relation to the vascularization process. The regenerating tissue showed cells with cavities resembling capillary central lumens and their cytoplasms revealed gold particles when they were immunostained for electron microscopy. Dark processes were seen in capillary-like lumens and, on other occasions, evaginations of endothelial cells were in contact with astroglial processes. These findings lead us to suggest that capillary-like structures might develop from cavitated astroglial cells, which would permit the migration of endothelial cells into their lumens. Astroglial-endothelial interactions persist until endothelial cells are morphologically differentiated. One possible interpretation of the present data is that astrocytes might participate directly and actively in the regulation of capillary formation.

\section{KEY WORDS}

astrocyte, GFAP, vascularization, transplant, rat

Reprint address:

Dr. I. Suárez

Departamento de Biología Celular y Genética Universidad de Alcalá, Alcalá de Henares

28871 Madrid, Spain

\section{INTRODUCTION}

Transplant survival necessarily depends upon the development of an effective blood supply. Most studies on vascularization with transplants have been performed by implanting either solid grafts or dissociated fragments. In solid grafts, the vascular network is already present before implantation $/ 16,20,29 /$ and the blood vessels of the graft must connect to those of the host. When dissociated tissue is transplanted, the blood vessels are disrupted and a complete vascular network must be formed $/ 8 /$, but donor endothelial cells are present in the suspension. It has been suggested that the vasculature develops from host endothelial cells /27/; however, other studies have suggested that endothelial cells from both the donor and the host participate in the vascularization of a brain transplant $/ 16,20 /$. When primary astrocyte cultures are implanted no donor endothelial cells are present in the implant and the blood vessels in the restoring tissue must be newly created.

It is well known that brain microvessels are entirely covered by astrocytes $/ 28,30 /$. Brain endothelial cells and perivascular astrocytes form an endothelial-astrocytic complex; the interactions between endothelial cells and astrocytes have been extensively investigated and astrocytes have been implicated in the induction of the blood-brain barrier $12,4,14,24,25,26,37 /$. Since it has been shown that astrocytes are able to participate in in vivo /14/ and in vitro angiogenesis $/ 18 /$, we implanted cultured astroglial cells into adult rat cerebral cortex to study the role of astrocytes in influencing endothelial cell behavior in the angiogenesis process in the implant zone, where no endothelial cells are present. New brain blood vessel growth has been described at 4 days after transplantation $/ 20 /$, coincident with the maximum rate of astroglial migration $/ 9 /$, so this paper studies the astrocyte response in the 
vascularization process 5 days post-implant. This time point is important to know the extent to which astroglial cells might participate in the angiogenesis of the transplant before host endothelial cells penetrate the implanted zone.

\section{MATERIALS AND METHODS}

\section{Cell cultures}

Rat astrocytes were prepared as previously described $/ 10 /$. Briefly, hypothalami were dissected out of rat fetuses (gestational age 15-16 days), minced and the cells dispersed in DMEM-Hams's F12 containing $10 \%$ FCS. The cell suspension was pelleted; cells were resuspended in fresh DMEMF12 medium, plated into poly-L-lysine coated dishes and incubated in a serum-free medium for 9 days.

\section{Transplantation}

For grafting to animals, cultures were resuspended to make a final concentration of $9 \times 10^{4}$ cells per $\mu 1$. Recipient rats were anesthetised with pentobarbital and placed in a stereotaxic instrument. Implants were made by stereotaxic injection of a 10 $\mu 1$ cell suspension using a Hamilton syringe. The wound was closed and the animals allowed to survive for 5 days before sacrifice.

\section{Immunohistochemistry for light microscopy}

Male Sprague-Dawley rats were anesthetized with ether and perfused transcardially with a mixture of $3 \%$ paraformaldehyde and $0.3 \%$ glutaraldehyde in $0.1 \mathrm{M}$ phosphate buffer ( $\mathrm{pH} 7.2)$. Brains were removed, postfixed for $4 \mathrm{~h}$ in the same fixative used for perfusion and then transferred to buffer, before processing for paraffin embedding. Transverse sections of the cerebral cortex were cut at a thickness of $8 \mu \mathrm{m}$.

GFAP immunohistochemistry was prepared as previously described $/ 36 /$. In brief, deparaffined sections were treated with swine non-immune serum at a dilution 1:30 for $30 \mathrm{~min}$, incubated overnight at $4^{\circ} \mathrm{C}$ in GFAP antiserum (Dakopatts) diluted 1:500. After washing, sections were incubated in swine anti-rabbit IgG, diluted 1:50 for
$1 \mathrm{~h}$, washed in Tris buffer and incubated in PAP complex. Peroxidase activity was revealed with $0.03 \% \mathrm{DAB}$ and $0.005 \% \mathrm{H}_{2} \mathrm{O}_{2}$. Omission of the first antibody was used as a specific control; staining was absent under this condition.

\section{Preparation of tissue for electron microscopy}

Rats were anesthetised and perfusion-fixed as described for light microscopy. The portions of brain containing the implants were removed, postfixed in $1 \%$ osmium tetroxide for $1 \mathrm{~h}$ and stained en bloc in saturated aqueous uranyl acetate at $4^{\circ} \mathrm{C}$ overnight. Blocks were dehydrated in acetone and embedded in Araldite. The tissue blocks were thin sectioned and processed sequentially for the morphological study of the implanted tissue and for post-embedding immunogold labelling.

\section{Immunohistochemistry for electron microscopy}

Ultrathin sections (mounted on uncoated nickel grids) were processed for immunogold labelling. Briefly, sections were treated with $9 \% \mathrm{NaIO}$ in $\mathrm{H}_{2} \mathrm{O}$ for $15 \mathrm{~min}$, washed in distilled water and then washed in Tris buffer. Sections were incubated in GFAP antiserum diluted 1:100 in Tris buffer for 24 $h$ at $4^{\circ} \mathrm{C}$. Following jet wash with Tris buffer, the grids were incubated in 1:50 IgG swine anti-rabbit gold $10 \mathrm{~nm}$ (Dakopatts) for $1 \mathrm{~h}$ at $20^{\circ} \mathrm{C}$. The grids were carefully washed first with Tris buffer and then with distilled water. The sections were contrasted with lead citrate. To control for non-specific staining, adjacent sections were incubated in nonimmune serum as the primary antibody followed by the IgG-gold.

\section{RESULTS}

Cultured astroglial cells derived from the embryonic rat hypothalamus were injected into the adult rat cerebral cortex, and the neovascularization and astrocytic reaction at the site of implant was examined by GFAP immunohistochemistry and electron microscopy at 5 days post-implant. The vascular network in the intact cortex was studied on the side opposite the transplant in each case. 
The lesioned area was characterized by the disruption of neuronal organization and an increase in the GFAP immunoreactivity around the needle track and its close surroundings. The cultured astrocytes in the implantation zone were packed and did not react to GFAP immunostaining; blood vessels were not observed within the implant. On the contrary, the cells on the edges of the implantation zone showed GFAP immunostaining (Fig. 1) and small blood vessels were clearly seen (Fig. 1c). The straight, long GFAP immunopositive processes were orientated radially toward the implant (Figs. 1a,1c) and were also seen around many small blood vessels (Figs. 1b,1c).

Electron microscopic observations were made of the graft-host interface next to the graft, an intermediate zone and, lastly, an area close to the undisturbed host tissue. The regenerating tissue next to the graft showed numerous cells and cellular debris and also contained cells with cavities that resembled the endothelial cavities (Figs. 2-4). These capillary-like cells displayed an irregular shape, probably due to the onset of cavitation that takes place in them; their cytoplasms were moderately electron-dense and numerous organelles were visible. The lumens had an irregular perimeter and contained cellular debris and/or amorphous material (Figs. 2-4). A complete basal lamina was formed on the outer surface membrane of cavitated cells (Figs. 2,4). When adjacent sections were GFAP-gold immunostained, these cells showed gold particles in the cytoplasm of the capillary forming cells (Figs: $3 c, 4 b)$.

Fragments of electron-dense structures in apposition to the internal membrane of the blood vessel in formation were also observed in the regenerating tissue of the intermediate zone (Fig. 5). These fragments could represent migrating endothelial cell processes.

Other capillary structures showed a large central lumen and were characterized by the presence of evaginations directed to the perivascular cells (Figs. $6 a-c)$. Coinciding with these zones in the capillary structures, the basal membrane exhibited disrupted areas that left zones open for contact between capillary-like cells and perivascular processes. On these occasions, no gold immunostaining was observed in the cytoplasm of the capillary-forming cells. Mitotic figures (Fig. 7a) and centrioles (Fig. 7b) were observed in cells that bordered the more morphologically developed blood vessels that were close to the undisturbed tissue.

The vascular network observed on the side opposite to the implant in each case showed the typical characteristics of developed blood vessels without either morphological ultrastructural alterations or gold particle deposits when sections were GFAP immunostained.

\section{DISCUSSION}

Endothelial cells invade the developing brain during its vascularization $/ 23,34 /$ by perforating the basement membrane and penetrating between the glial endfeet which form the glial external limiting membrane $/ 23 /$, probably stimulated by brainderived angiogenic factors $/ 31 /$. Microvessel formation occurs close to astrocytic cell processes $13 /$, which are progressively covered by GFAP immunopositive processes $/ 36 /$. In our study, there was increased GFAP immunoreaction at the edges of the implant and it was mainly related to blood vessels; these findings support the widely accepted evidence that astrogliosis and new blood vessel formation are typical of CNS reaction to injury.

Interestingly, the presence of astrocytes always coincides with the presence of blood vessels in the retina /32,35/; astrocytes are detectable several days before the first intraretinal blood vessels can be observed /33/, suggesting that the presence and distribution of astrocytes may determine the developing blood vessel pattern in the retina /33/. In addition, it has recently been suggested $/ 38 /$ that the regional heterogeneity of brain microvessels may be caused by astrocytic heterogeneity and, since astrocytes participate in the secretion of angiogenetic factors which stimulate neovascularization $/ 11,21 /$, it could be suggested that the presence and distribution of astrocytes might determine the pattern of blood vessel development in the regenerating tissue. The findings described here might support the belief that perivascular astrocytes directly influence the final developmental events of endothelial cells in the CNS /4,14,34/, and they might also play a very important role in inducing endothelial cells to form capillary structures in vivo. 


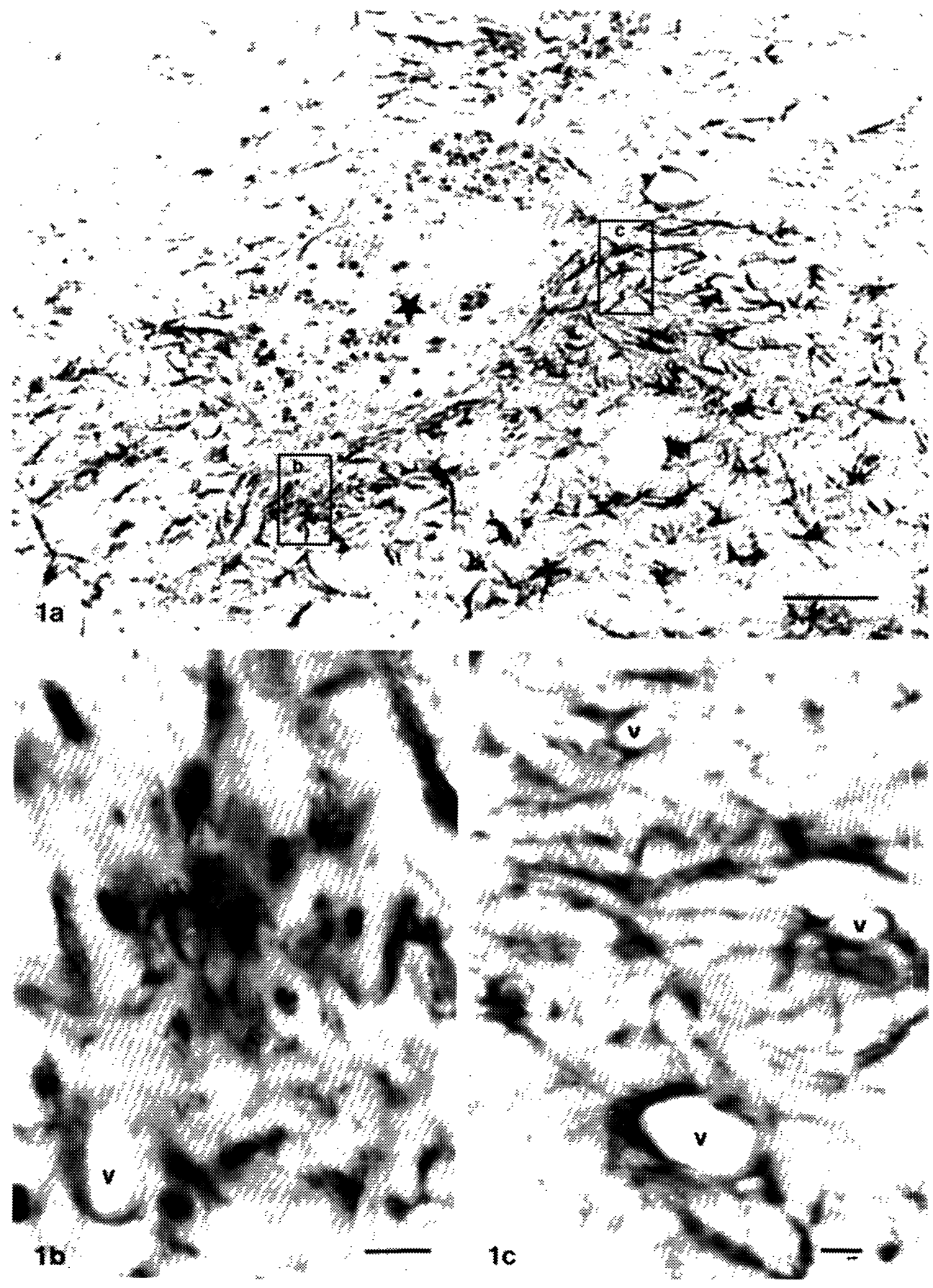

Fig. 1: a: Cultured astrocytes after implantation into the adult cerebral cortex on day 5 post-grafting ( $\star$ ). Immunoreactive astrocytes stained with GFAP antiserum are mainly found in the periphery of the graft; their GFAP positive processes are radially directed toward the implant. Similar areas, delineated (b) and (c), in the graft-host interface zone are presented in higher power in b and c. (Bar: $50 \mu \mathrm{m}$ ). b: Magnification from a similar zone, indicated by (b), showing GFAP immunopositive profiles irregularly distributed; some of them are associated with blood vessels (v). (Bar: $5 \mu \mathrm{m}$ ). c: High Magnification at the edge of the implant (indicated by c). GFAP immunoreactive processes are radially oriented and most of them are associated with blood vessels (v). (Bar: $5 \mu \mathrm{m})$. 

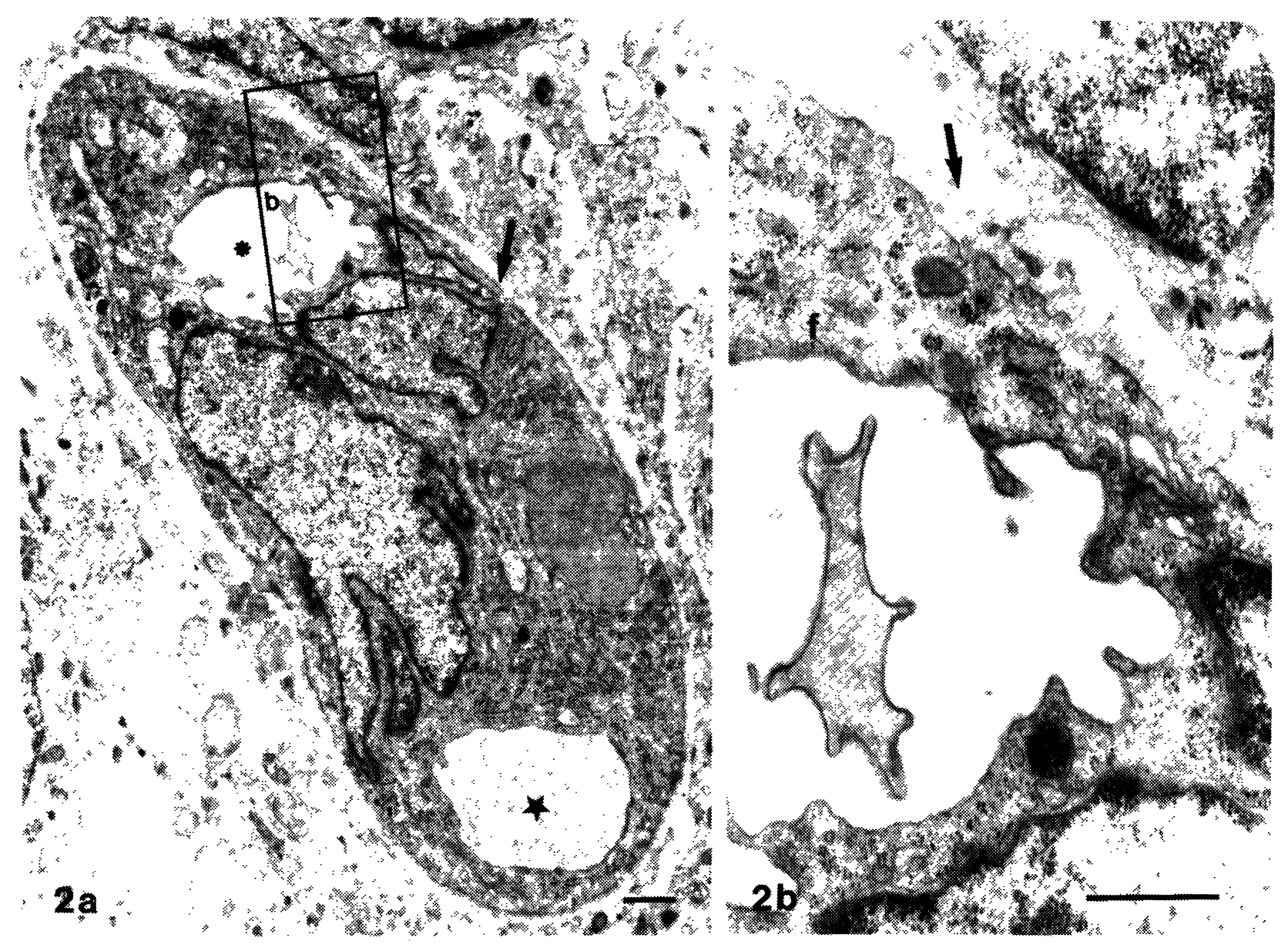

Fig. 2: a: Electron photomicrograph of a cavitated cell in the graft-host interface showing irregular nucleus, numerous organelles and cavities. These cavities exhibit cellular debris (*) or amorphous electron-lucent material ( $\star$ ). Basal membrane (arrow). (Bar: $1 \mu \mathrm{m}$ ). b: Detail of a; a portion of the cavitated cell, which shows protrusions and cellular debris in the lumen. f: intermediate filaments. The basal membrane (arrow) exhibits irregular distribution.

(Bar: $0.5 \mu \mathrm{m}$ ).

This study has shown progressive development in the vascularization process from the edges of the implant, where capillary-like structures were observed, to zones close to the intact host tissue, where the blood vessels exhibited features like those of more developed capillaries. This could be interpreted as the different steps that a blood vessel follows during its neoformation. Several characteristics associated with the degree of vascularization must be considered in our study.

First, the cells with cavities resembling central lumens and located at the edges of the implant are consistent with capillary-like structures observed in vitro $/ 18 /$; the presence of gold particles in the cavitated cells at 5 days post-implant might determine the astroglial character of these cells, unlike in vitro observations which showed that the capillary forming cells had an endothelial lineage $/ 18 /$.

Second, our observations of electron-dense processes located within the lumens and probably belonging to endothelial cells, which can penetrate astroglial lumens, lead us to suggest that astrocytes could serve as a migrating route for the displacement of the endothelial cells during in vivo angiogenesis. It is known that cultured astrocytes secrete a factor (or factors) which has potent migration stimulating activity for endothelial cells 


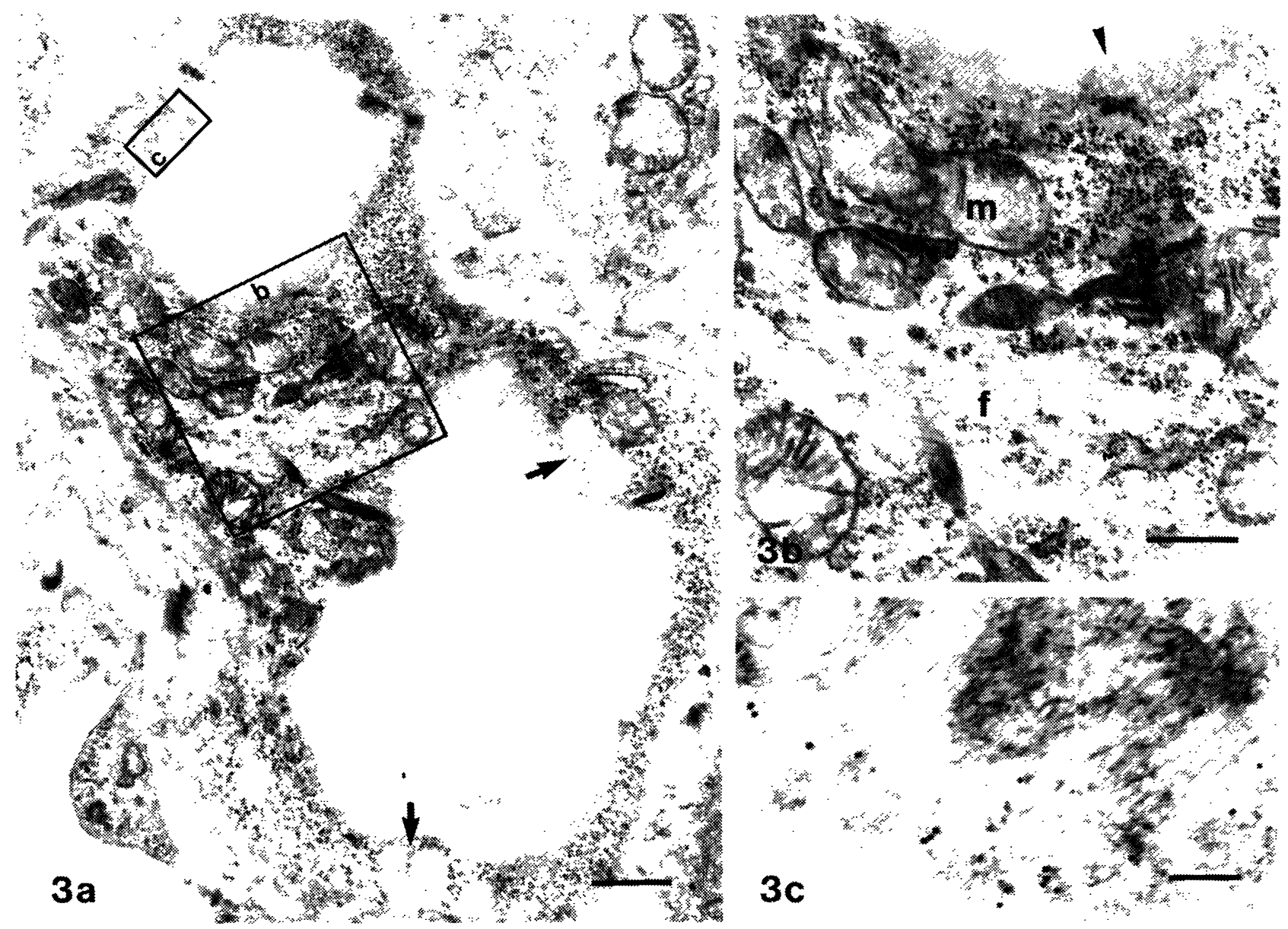

Fig. 3: a: Irregular cell showing two large cavities and numerous organelles. Lipid bodies (arrows) are seen within the cytoplasm. (Bar: $1 \mu \mathrm{m}$ ). b: Higher power of the cytoplasm interposed between the two cavities, delineated (b) in a, exhibiting numerous intermediate filaments (f), ribosomes and mitochondria (m). The luminal surface shows difuse material (arrow-head). (Bar: $0.5 \mu \mathrm{m}$ ). c: Adjacent section of the area delineated (c) in a, showing immunogold particles associated with intermediate filaments. (Bar: $0.1 \mu \mathrm{m})$.

/13/. In addition, both in vivo /14/ and in vitro /19/ studies have proved that astrocytes induce endothelial cells to form capillaries, although the mechanism by which endothelial cells interact with specific signals to form capillaries is not yet clear. Taking these data into account, one interpretation is that the host endothelial cells are attracted from the host tissue by implanted astrocytes, as has been demonstrated in the anterior eye chamber $/ 14 /$, and are then induced to reorganize in the astrocytic lumens.

Finally, the stimulated endothelial cells would form the new blood vessels by means of successive cell divisions; this suggestion is based on the presence of centrioles in the cytoplasm of the endothelial cells, as well as the observation of mitotic figures in the cells which form the vessel walls. Further support of this notion can be found in previous reports that astrocytes generate signals that induce endothelial cell division $/ 12,15 /$. Moreover, not only do astrocytes induce endothelial cells to form the tight junctions to develop the blood-brain barrier in most vertebrates $/ 2,14,25,26,37 /$, but in elasmobranch fish the perivascular astrocytes, not the endothelial cells, form the blood-brain barrier /1,7/. These considerations and the immunohistochemical data from the present study might suggest that astrocytes 


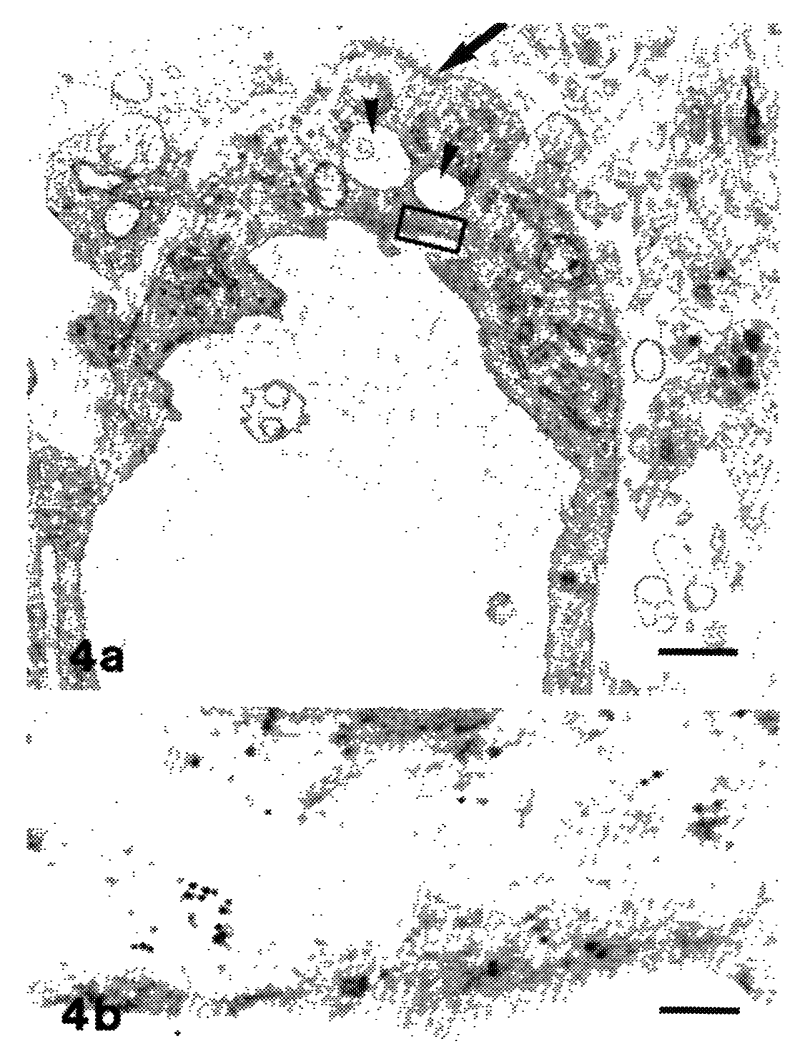

Fig. 4: a: Cavitated cell in the graft-host interface showing a large central lumen, as well as two small cavities (arrow-heads). Basal membrane (arrow). (Bar: $1 \mu \mathrm{m}$ ). b: An adjacent section of the delineated area in a is shown at higher power exhibiting immunogold particles in relation to intermediate filaments. (Bar: $0.1 \mu \mathrm{m}$ ).

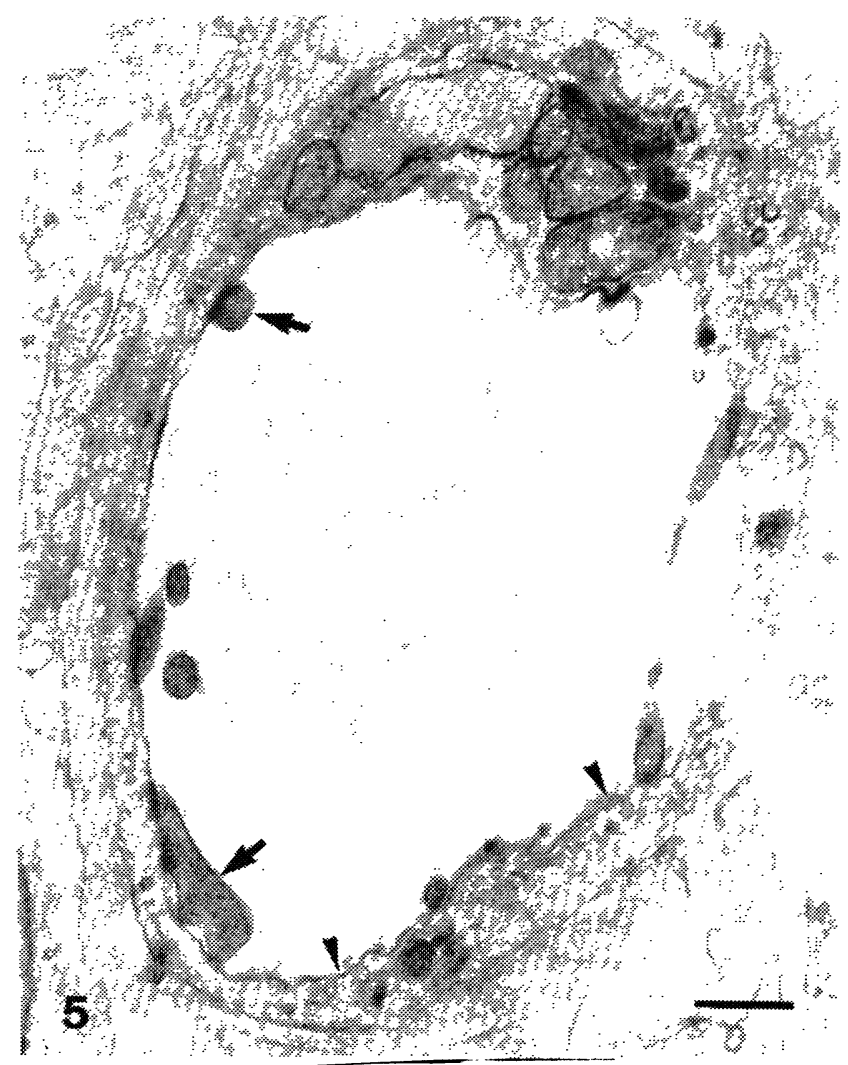

Fig. 5: Capillary-like structure located in the intermediate zone between the graft and the intact tissue Electron-dense processes (arrows) are in contact with the luminal surface of the cavitated cell. The luminal surface shows vesicles (arrow-heads) associated with the membrane and amorphous material in their surroundings. (Bar: $0.5 \mu \mathrm{m}$ ).
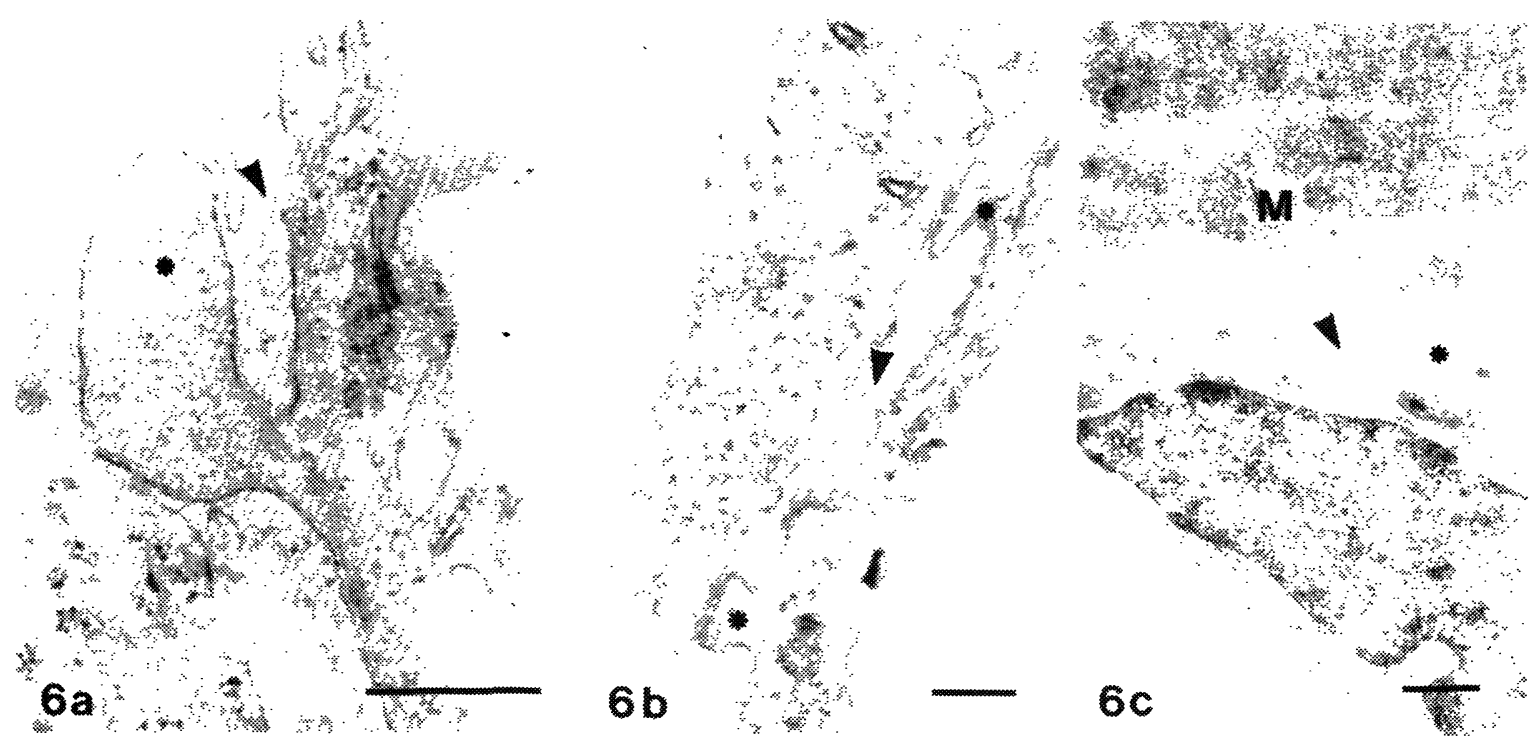

Fig. 6: Evaginations (*) of endothelial cells near the undisturbed cerebral cortex. These evaginations can be associated with cell bodies (a), processes (b) or mitotic figures (M) (c) of perivascular cells. The irregular basal membrane (arrowheads) which surrounds the capillary cells is disrupted at the evaginations to permit contact between the two cellular types. (Bars: $0.5 \mu \mathrm{m}$ ). 


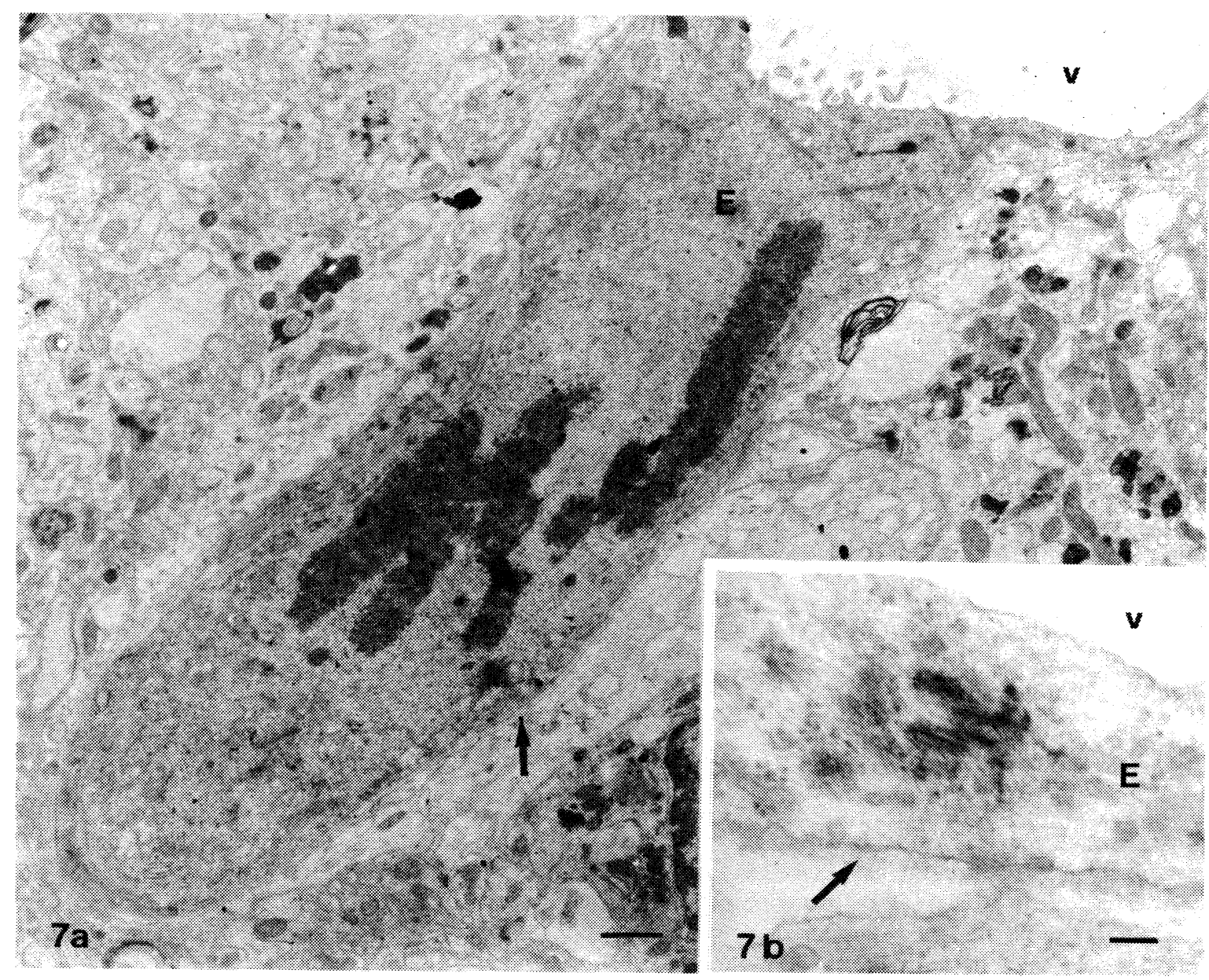

Fig. 7: a: Mitotic endothelial cell $(\mathrm{E})$ in the restored tissue, which is surrounded by a complete basal membrane (arrow). v: blood vessel. (Bar: $1 \mu \mathrm{m})$. b: Centriole within endothelial cell $(\mathrm{E})$ in the same restored zone. v: blood vessel. Basal membrane (arrow). (Bar: $0.1 \mu \mathrm{m})$.

participate directly in the vascularization process.

It has been postulated that astrocytes participate in the formation of the basal lamina in both in vivo $/ 5 /$ and in vitro $/ 17,22 /$ studies. It is well known that cultured astrocytes, surrounded by a basal lamina, migrate into adult host brain following transplantation $/ 39 /$. In this study, the cavitated astrocytes are surrounded by a complete basal membrane at five days post-implant, which agrees with observations of Bernstein et al. /5/ who observed a morphologically-normal basal membrane by 5 days. In addition to the basal membrane surrounding the cavitated cells, which could suggest that they belong to cultured astrocytes, another basal membrane is secreted between astrocytes and endothelial cells in the more developed blood vessels; however, contacts between endothelial and astroglial cells are observed in zones where the basal membrane is disrupted. It has been suggested that close endothelial-astroglial contacts are necessary to generate an in vitro endothelial morphogenic response $/ 19,25 /$. Our findings lead us to speculate that very close astroglial-endothelial apposition would be required for capillary induction, because the basement membrane is disrupted in certain zones, which may allow interactions between endothelial and astroglial cells. If the formation of capillary-like structures in vitro can result from changes in the expression of endothelial cell surface adhesion molecules /19/, these adhesion molecules could be present in the capillary formation in vivo and might mediate the rearrangement of endothelial cells described in this report. The close astroglial-endothelial apposition 
would remain until the complete differentiation of the blood vessel, since basal membrane formation is thought to be one of the last steps of in vivo capillary formation $/ 3 /$.

In summary, it is tempting to speculate that the capillary formation subsequent to an implant of cultured astrocytes might be divided into three steps: 1. the induction and formation of central lumens within specific astroglial-like cells, as is suggested by the deposit of gold particles in their cytoplasms; 2 . the host endothelial migration into the lumens in these activated "astroglial" cells, and 3. the proliferation of endothelial cells to form morphologically developed capillaries. The data of Cancilla et al. /6/ differ from ours in that the progressive association of astrocytes with newly formed vessels during microvessel regeneration after injury suggested that astrocytes migrated to the blood vessel. In our study, in contrast, we interpret that endothelial cells might migrate to the activated astrocytes to form new blood vessels. Further studies to identify the molecular basis for astroglial activation, central lumen formation and the participation of donor and/or host astrocytes in the vascularization process are needed.

\section{ACKNOWLEDGEMENTS}

The authors thank Mr. A. Priego for his technical help and Ms. C.F. Warren (ICE, Universidad de Alcalá) for her assistance in the stylistic revision of the manuscript. This study was supported by grants DGICYT PB86-0152 and U.A.H. 91 A/4.

\section{REFERENCES}

1. Abbott NJ, Butt AM. Permeability of the dogfish glial blood-brain barrier to ions and small molecules. J Physiol 1986; 377: 103.

2. Arthur FE, Shivers RR, Bowman PD. Astrocytemediated induction of tight junctions in brain capillary endothelium: an efficient in vitro model. Dev Brain Res 1987; 36: 155-159.

3. Bar TH, Wolff JR. The formation of capillary basement membranes during internal vascularization of the rat's cerebral cortex. Z Zellforsch 1972; 133: 231-248.

4. Beck DW, Vinters HV, Hart MN, Cancilla PA. Glial cells influence polarity of the blood-brain barrier. J Neuropathol Exp Neurol 1984; 43: 219-224.

5. Bernstein JJ, Getz $R$, Jefferson $M$, Kelemen $M$. Astrocytes secrete basal lamina after hemisection of rat spinal cord. Brain Res 1985; 327: 135-141.

6. Cancilla PA, Berliner JA, Bready JV. Astrocytes and the blood-brain barrier: kinetics of astrocyte activation after injury and induction affects on endothelium. In: Pathophysiology of the Blood-Brain Barrier: Long Term Consequences of Barrier Dysfunction for the Brain. Amsterdam: Elsevier, 1990; 31.

7. Cserr HF, Bundegaard M. Blood-brain interface in vertebrates: A comparative approach. Ann J Physiol 1984; 246: 277-288.

8. Dusart I, Nothias F, Roudier F, Besson JM, Peschanski $M$. Vascularization of fetal cell suspension grafts in the excitotoxically lesioned adult rat thalamus. Dev Brain Res 1989; 48: 215-228.

9. Emmett CJ, Lawrence JM, Raisman G, Seeley PJ. Cultured epithelioid astrocytes migrate after transplantation into the adult rat brain. J Comp Neurol 1991; 310: 330-341.

10. García-Segura LM, Torres-Alemán I, Naftolin F. Astrocytic shape and glial fibrillary acidic protein immunoreactivity are modified by estradiol in primary rat hypothalamic cultures. Dev Brain Res 1989; 47 : 298-302.

11. Giulian D, Woodward J, Young D, Krebs J, Lachman L. Interleukin-1 injected into mammalian brain stimulates astrogliosis and neovascularization. $J$ Neurosci 1988; 8: 2485-2490.

12. Glaser BM. Cell biology and biochemistry of endothelial cells and the phenomenon of intraocular neovascularization. In: Adler $R$, Faber $D$, eds, The Retina: A Model for Cell Biology Studies, Part II. Orlando: Academic Press, 1986; 215-243.

13. Ishizaki $Y$, Kanayasu $T$, Murota S. A migration stimulating factor for vascular endothelial cells is released by cultured astrocytes. Proc Japan Acad 1990; 66: 81-83.

14. Janzer RC, Raff MC. Astrocytes induce blood-brain barrier properties in endothelial cells. Nature 1987; 325: 253-257.

15. Korr H. Proliferation and cell cycle parameters of astrocytes. In: Fedoroff $S$, Vernadakis $A$, eds. Astrocytes: Cell Biology and Pathology of Astrocytes, Vol 3. New York: Academic Press, 1986; 77-127.

16. Knum JM, Rosenstein JM. Patterns of angiogenesis in neural transplant models. II. Fetal neocortical transplants. J Comp Neurol 1988; 271: 331-345.

17. Kusaka H, Hirano A, Bornstein MB, Raine CS. Basal lamina formation by astrocytes in organotypic cultures of mouse spinal cord tissue. J Neuropathol Exp Neurol 1985; 44: 295-303.

18. Laterra J, Goldstein GW. Astroglial-induced in vitro angiogenesis: Requirements for RNA and protein synthesis. J Neurochem 1991; 57: 1231-1239. 
19. Laterra J, Guerin C, Goldstein GW. Astrocytes induce neural microvascular endothelial cells to form capillary-like structures in vitro. J Cell Physiol 1990; 144: 204-215.

20. Lawrence JM, Huang SK, Raisman G. Vascular and astrocytic reactions during establishment of hippocampal transplants in the adult host brain. Neuroscience $1984 ; 12:$ 745-760.

21. Lieberman A, Pitha P, Shin H, Shin M. Production of tumor-necrosis-factor and other cytokines by astrocytes stimulated with lipopolysaccharides or a neurotropic virus. Proc Natl Acad Sci USA 1989; 86: 6348-6352.

22. Liesi $P$, Dahl D, Vaheri A. Laminin is produced by early rat astrocytes in primary culture. J Cell Biol 1983; 96: 920-924.

23. Marin-Padilla $M$. Embryonic vascularization of the mammalian cerebral cortex. In Cerebral Cortex, Vol 7. New York: Plenum Press, 1988; 479-509.

24. Maxwell K, Berliner JA, Cancilla PA. Stimulation of glucose analogue uptake by cerebral microvessel endothelial cells by a product released by astrocytes. J Neuropathol Exp Neurol 1989; 48: 69-80.

25. Meyer J, Rauh J, Galla H-J. The susceptibility of cerebral endothelial cells to astroglial induction of blood-brain barrier enzymes depends on their proliferative state. J Neurochem 1991; 57: 1971-1977.

26. Minakawa T, Bready J, Berliner J, Fisher M, Cancilla PA. In vitro interaction of astrocytes and pericytes with capillary-like structures of brain microvessel endothelium. Lab Invest 1991; 65: 32-40.

27. Mrejen S, Quinonero J, Moinard F, Ghandour S, Jacque C. Xenogenic transplantation into newborn rodent brain: neovascularization of the graft by the host. Dev Neurosci 1992; 14: 144-152.

28. Peters A, Palay SL, Webster HD. The fine structure of the nervous system. The neurons and the supporting cells. Philadelphia: Saunders, 1976; 231-263.

29. Raisman G, Lawrence JM, Zhou CF, Lindsay RM. Some neuronal, glial and vascular interactions which occur when developing hippocampal primordia are incorporated into adult host hippocampi. In: Björklund A, Stenevi U, eds. Neural Grafting in the Mammalian CNS. Amsterdam: Elsevier 1985; 125-150.

30. Ramón y Cajal S. Histologie du système nerveux de l'homme et des vertébrés. Maloine, Paris 1911 (reprinted Madrid: Instituto Ramón y Cajal, CSIC 1972; 230-252).

31. Risau W, Wolburg H. Development of the blood-brain barrier. Trends Neurosci 1990; 13: 174-178.

32. Schnitzer J. Retinal astrocytes: Their restriction to vascularized parts of the mammalian retina. Neurosci Lett 1987; 78: 29-32.

33. Schnitzer J. The development of astrocytes and blood vessels in the postnatal rabbit retina. J Neurocytol 1988; 17: 433-449.

34. Steward PA, Wiley MJ. Developing nervous tissue induces formation of blood-brain barrier characteristics in invading endothelial cells: a study using quail-chick transplantation chimeras. Dev Biol 1981; 84: 183-192.

35. Stone J, Dreher $Z$. Relationship between astrocytes, ganglion cells and vasculature of the retina. J Comp Neurol 1987; 255: 35-49.

36. Suárez I, Fernández $B$, Bodega G, Tranque $P$, Olmos G, García-Segura LM. Postnatal development of glial fibrillary acidic protein immunoreactivity in the hamster arcuate nucleus. Dev Brain Res 1987; 37: 8995.

37. Tao-Cheng J-H, Brightman MW. Development of membrane interactions between brain endothelial cells and astrocytes in vitro. Int $J$ Dev Neurosci 1988; 6: 2537.

38. Wolff JEA, Belloni-Olivi L, Bressler JP, Goldstein GW. Gamma-glutamyl transpeptidase activity in brain microvessels exhibits regional heterogeneity. J Neurochem 1992; 58: 909-915.

39. Zhou HF, Lee LH-Ch, Lund RD. Timing and patterns of astrocyte migration from xenogenic transplants of the cortex and corpus callosum. J Comp Neurol 1990; 292: $320-330$. 

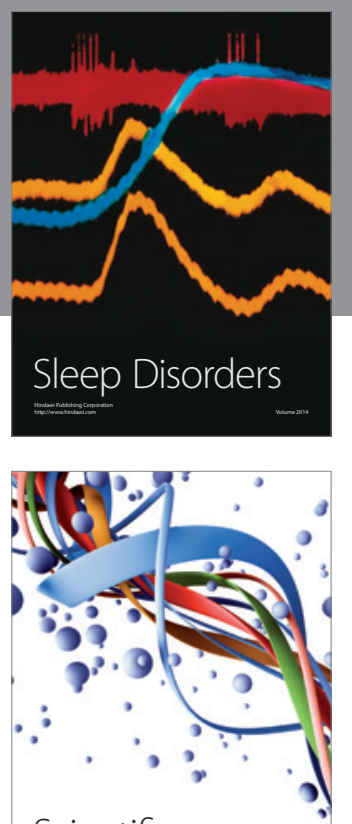

Scientifica
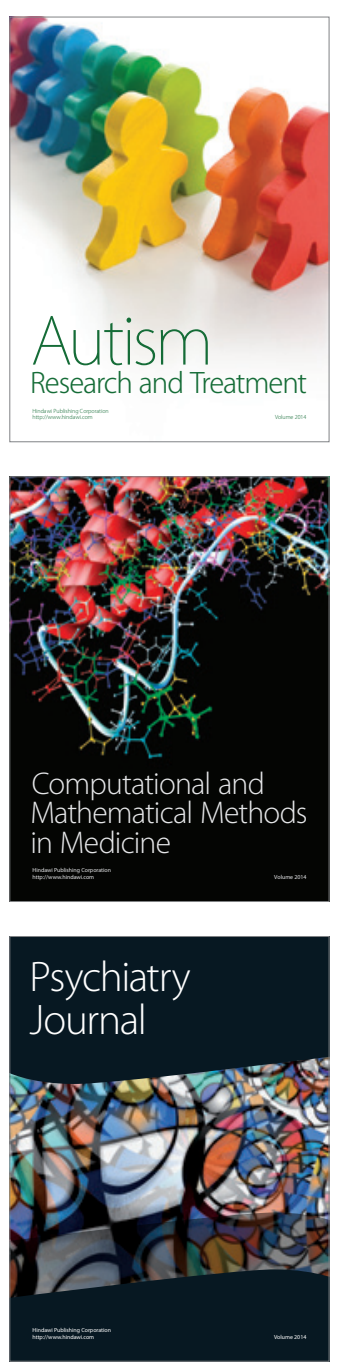
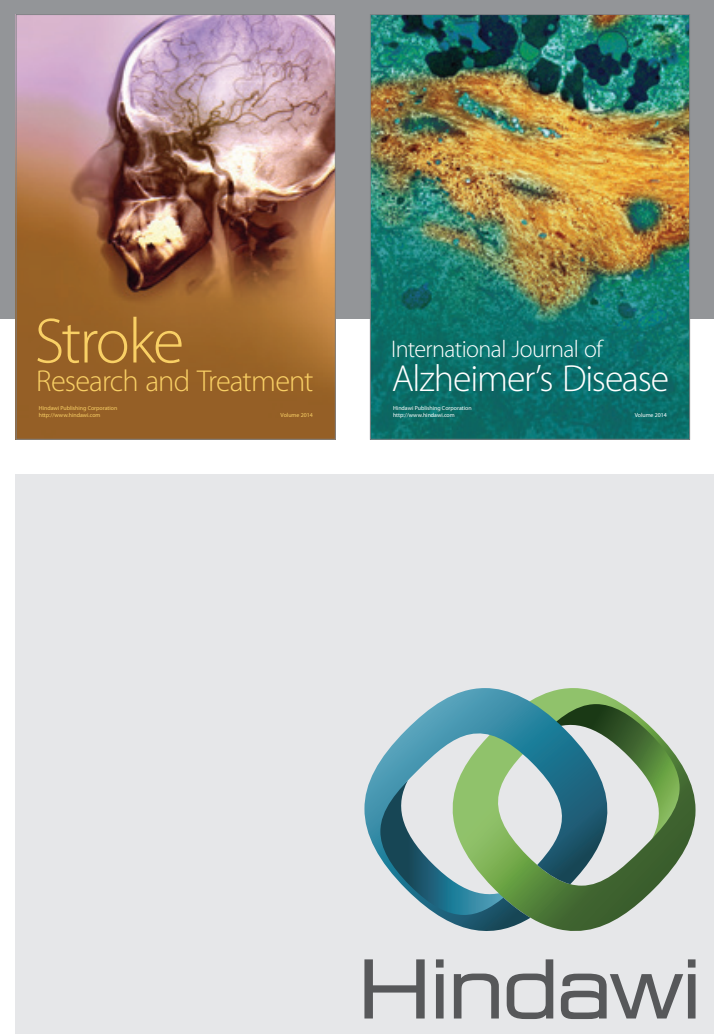

Submit your manuscripts at

http://www.hindawi.com
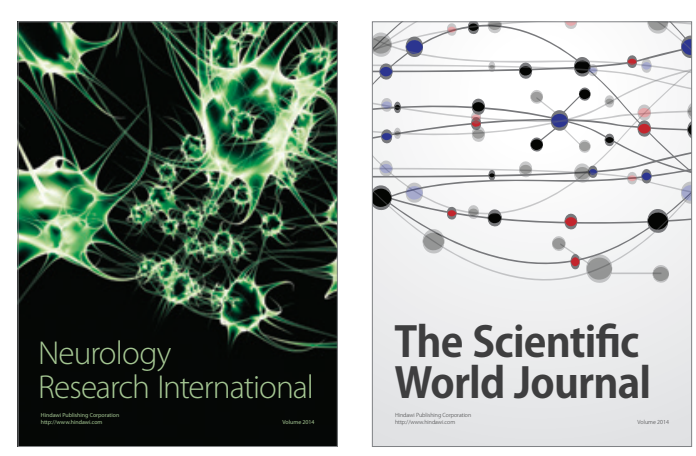

The Scientific World Journal

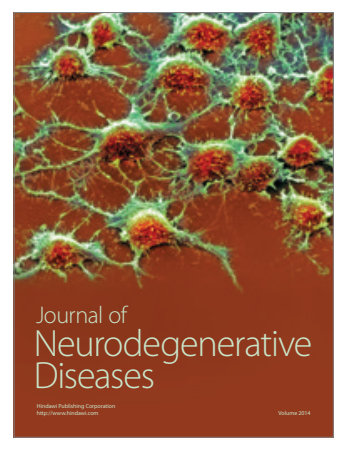

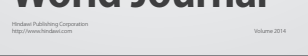

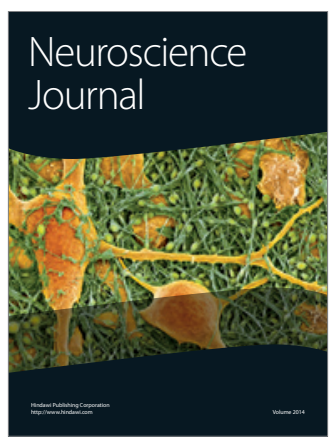

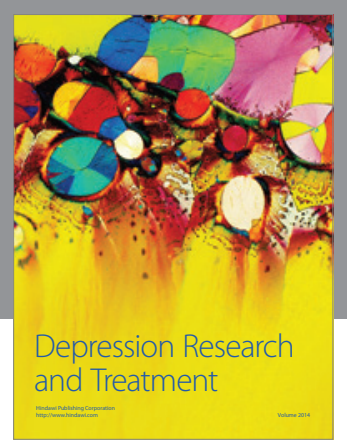
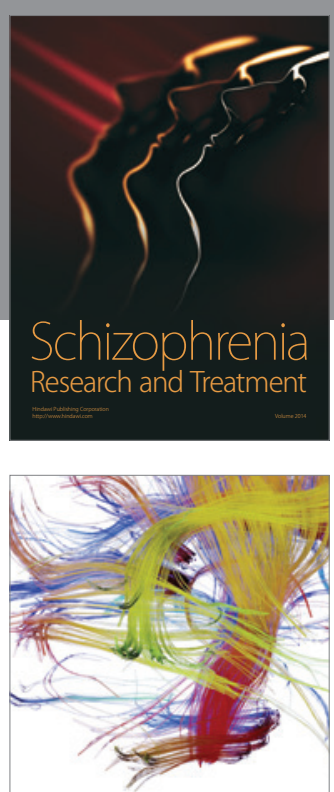

Brain Science

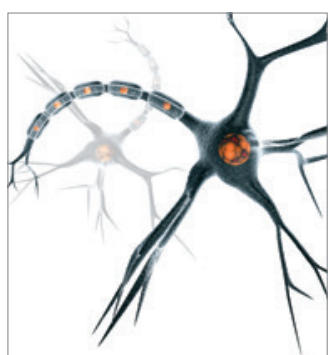

Neural Plasticity
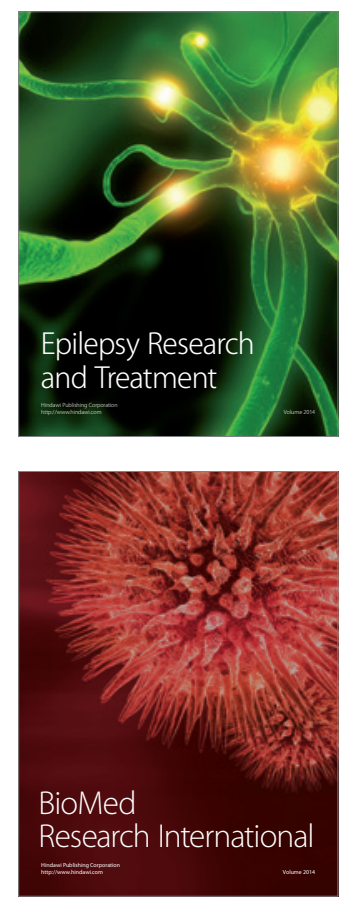

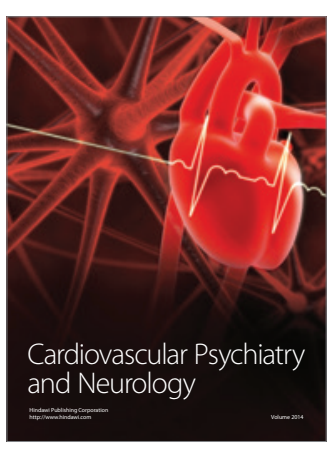

Parkinson's

Disease
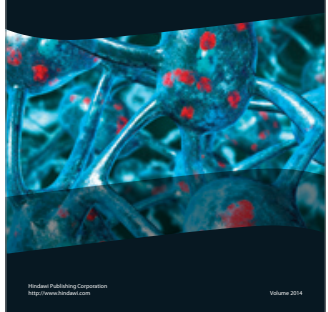